\title{
EXPLORATORY ANALYSIS OF DIETARY INTAKE AND BRAIN IRON ACCUMULATION DETECTED USING MAGNETIC RESONANCE IMAGING IN OLDER INDIVIDUALS: THE LOTHIAN BIRTH COHORT 1936
}

\author{
M. DEL C. VALDÉS HERNÁNDEZ ${ }^{1,2}$, J. ALLAN ${ }^{3}$, A. GLATZ1 ${ }^{1}$ J. KYLE ${ }^{4}$, J. CORLEY ${ }^{5}$, C.E. BRETT ${ }^{5}$, \\ S. MUÑOZ MANIEGA ${ }^{1,2}$, N.A. ROYLE ${ }^{1,2}$, M.E. BASTIN ${ }^{1,2}$, J.M. STARR ${ }^{6}$, I.J. DEARY ${ }^{2,5}$, J.M. WARDLAW $^{1,2}$

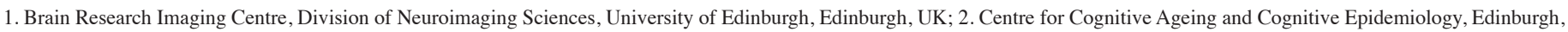 \\ UK; 3. Health Psychology, Division of Applied Health Sciences, University of Aberdeen, Aberdeen, UK; 4. Public Health Nutrition, Division of Applied Health Sciences, University \\ of Aberdeen, Aberdeen, UK; 5. Department of Psychology, University of Edinburgh, Edinburgh, UK; 6. Department of Geriatric Medicine, University of Edinburgh, Edinburgh, UK. \\ Corresponding author: Dr. Maria C. Valdés Hernández, Brain Research Imaging Centre, Department of Neuroimaging Sciences, University of Edinburgh, Western General Hospital, \\ Crewe Road, Edinburgh EH4 2XU, UK. Telephone: +44-131-537-3093, Fax: +44-131-332-5150, E-mail: mvhernan@staffmail.ed.ac.uk
}

\begin{abstract}
Context: Brain Iron Deposits (IDs) are associated with neurodegenerative diseases and impaired cognitive function in later life, but their cause is unknown. Animal studies have found evidence of relationships between dietary iron, calorie and cholesterol intake and brain iron accumulation. Objectives: To investigate the relationship between iron, calorie, and cholesterol intake, blood indicators of iron status, and brain IDs in humans. Design, Setting and Participants: Cohort of 1063 community-dwelling older individuals born in 1936 (mean age 72.7years, SD=0.7) with dietary information, results from blood sample analyses and brain imaging data contemporaneously in old age. Measurements: Magnetic Resonance Imaging was used to assess regional volumes of brain IDs in basal ganglia, brainstem, white matter, thalamus, and cortex/border with the corticomedullary junction, using a fully automatic assessment procedure followed by individual checking/ correction where necessary. Haemoglobin, red cell count, haematocrit, mean cell volume, ferritin and transferrin were obtained from blood samples and typical daily intake of iron, calories, and cholesterol were calculated from a validated food-frequency questionnaire. Results: Overall, $72.8 \%$ of the sample that had valid MRI ( $n=676)$ had brain IDs. The median total volume of IDs was $40 \mathrm{~mm} 3$, inter-quartile range (IQR)=196. Basal ganglia IDs (median=35, IQR=159.5 mm3), were found in $70.6 \%$ of the sample. IDs in the brainstem were found in $12.9 \%$ of the sample, in the cortex in $1.9 \%$, in the white matter in $6.1 \%$ and in the thalamus in $1.0 \%$. The median daily intake of calories was $1808.5 \mathrm{kcal}$ (IQR=738.5), of cholesterol was $258.5 \mathrm{mg}(\mathrm{IQR}=126.2$ ) and of total iron was $11.7 \mathrm{mg}(\mathrm{IQR}=5)$. Iron, calorie or cholesterol intake were not directly associated with brain IDs. However, caloric intake was associated with ferritin, an iron storage protein $(\mathrm{p}=0.01)$. Conclusion: Our results suggest that overall caloric, iron and cholesterol intake are not associated with IDs in brains of healthy older individuals but caloric intake could be associated with iron storage. Further work is required to corroborate our findings on other samples and investigate the underlying mechanisms of brain iron accumulation.
\end{abstract}

Key words: Iron, MRI, ageing, diet, cholesterol, calorie.

\section{Introduction}

There is increasing evidence that iron is involved in neurodegenerative diseases, and that as the brain ages, iron accumulates in regions linked to diseases like Parkinson's and Alzheimer's (1). Iron deposition load, mainly in the basal ganglia region, is negatively associated with general intelligence in healthy older adults (2). However, little is known about the mechanisms that lead to the formation of these brain iron deposits (IDs). Increased iron concentrations in the brain may result from the altered vascularisation that occurs during normal ageing, which is accentuated in neurodegenerative diseases $(3-5,6)$. Alternatively, iron accumulation may be related to the blood-brain barrier failure, with normal or pathological aging (1).

Animal studies have shown that short-term iron deprivation can be followed by persistent deficiency of non-haem brain iron (7) whereas excess dietary iron causes an increase in brain iron levels $(8,9)$. Dietary iron, however, is not the only dietary factor that has been associated with brain iron accumulation.
Diets containing high levels of vitamins C, E, B6 and B12, folate, unsaturated fatty acids, and fish oils (diets that are likely to limit the absorption of non-heme iron) are related to a reduction in the risk of Alzheimer's: a disease reported to be associated with elevated levels of brain iron (10). Rhesus monkeys fed a calorie restricted (but nutritionally equivalent to control) diet in middle age had significantly reduced brain iron accumulation in old age relative to animals fed a standard diet (11) and a study in rats (12) also yielded similar results. Similarly, rabbits fed a diet high in cholesterol experienced increased deposition of brain iron (13).

To date, there have been no large studies of the relationship between dietary iron, calorie and cholesterol intake and brain iron deposition in humans. In the present study, we explore the relationship between dietary iron, calorie, and cholesterol intake, blood indicators of iron status, and brain iron accumulation in a large, age-homogeneous group of community-dwelling older adults. We hypothesised that (a) dietary iron would be directly associated with haematological markers of iron and iron accumulation in the brain, and that (b) 
in line with animal studies, calorie/cholesterol intake would be associated with brain iron accumulation.

\section{Materials and Methods}

\section{Participants}

Study participants came from the Lothian Birth Cohort 1936 (LBC1936), which comprises community-dwelling older adults, most of whom participated in the Scottish Mental Survey as children in 1947 (14). Details of the full cohort test protocol are given elsewhere (14). In brief, 1091 individuals with an average age of $69.5(\mathrm{SD}=0.8)$ years enrolled the first data collection wave between 2004 and 2007, which involved completing cognitive tests, and providing personality, demographic, health, lifestyle, dietary information and blood samples. At a second wave, about three years later, 866 participants (mean age 72.7 years, SD 0.7 years) repeated almost all assessments from wave 1 with the exception of the dietary questionnaire, and a subgroup $(n=700)$ had an MRI brain scan. Written informed consent was obtained from all participants under protocols approved by the Lothian (REC 07/MRE00/58) and Scottish Multicentre (MREC/01/0/56) Research Ethics Committees.

\section{Magnetic Resonance Imaging (MRI) scans}

MRI data were acquired using a 1.5T GE Signa Horizon HDxt clinical scanner (General Electric, Milwaukee, WI, USA) using a self-shielding gradient set with maximum gradient of $33 \mathrm{mT} / \mathrm{m}$, and an 8-channel phased-array head coil. The imaging protocol is fully described elsewhere (15). Mineral deposits predominantly of iron content (IDs) were assessed using co-registered T1- and T2*-weighted MR volumes (16) on 676 valid and high quality imaging datasets, obtained from the 700 participants who initiated the brain MRI scanning session in wave 2 . The segmentation of the basal ganglia IDs was done using a fully automated procedure (17), and checked/ manually edited by an experienced analyst where required. IDs in the brainstem, white matter, thalamus and cortex/border with the corticomedullary junction were separately identified, extracted and quantified manually by the same expert using a validated technique $(2,18)$. ID measurements were corrected for intracranial volume and brain tissue volume to control for head and brain size respectively using procedures described in detail elsewhere $(2,15)$

\section{Haematological parameters}

Four hematologic measures commonly used to assess iron status were obtained at each testing wave: haemoglobin, red cell count, haematocrit (volume \% of red cells in blood) and mean cell volume out from blood samples processed fully automatically using the haematology analyser Sysmex XE-5000 (https://www.sysmex.com/US/en/Products/Hematology/ XESeries/Pages/XE-5000-Hematology-Analyzer.aspx). Two molecules that intervene in the storage and transport of non-heme iron were assessed at wave 2 and used to validate the possible path iron in blood $\rightarrow$ brain iron accumulation. These were: ferritin (a storage protein) and transferrin (a metalloprotein). From 1091 individuals who enrolled the study, 1062 provided blood samples in wave 1 ( 7 withdrawals and 22 deaths), and 825 in wave 2 . The main causes for withdrawal at wave 2 were death (19), lost contact (20), health reasons (64), dementia (7), care roles (13) and lack of time (17).

\section{Diet}

Typical daily intake of iron, calories, and cholesterol were calculated from responses to the Scottish Collaborative Group Food Frequency Questionnaire (SCG-FFQ) administered at wave 1. The SCG FFQ is a self-report instrument, validated for use with older adults (19), which asks about typical consumption of 175 foods and drinks grouped into 19 categories, plus foods and drinks not listed in the main questionnaire and dietary supplements. Respondents rate the frequency of consumption of standard portions of each food over the last 2-3 months (rarely/never, 1-3 per month, 1 per week, 2-3 per week, 4-6 per week, 1 per day, 2-3 per day, 4-6 per day or 7+ per day) and responses are used to estimate typical micro and macro nutrient intakes. All study participants $(n=1091)$ were asked to complete the SCG FFQ at home and return it by post. Of these, 98 were not returned, 26 were returned blank, and 39 had more than 10 missing items and were, therefore, excluded from the analyses.

\section{Demographics}

Gender and age at each data collection wave were used as covariates in all analyses.

\section{Statistical analysis}

Mann-Whitney U tests (from PASW Statistics 18) were used to determine whether the distributions of the haematological and imaging variables significantly differed between sexes or not. All blood iron-related parameters (haemoglobin, haematocrit ratio, mean cell volume and red cell count) were significantly higher in men than women $(\mathrm{p}<0.001)$. IDs in the brainstem $(\mathrm{p}=0.001)$ were different for men and women: on average, men had twice the volume of insoluble iron deposited in the brainstem and four times the volume of iron deposition in the cortex/corticomedullary junction than women. Therefore, all tests were adjusted for gender, in addition to age in days at the time of each test. We applied robust univariate linear regression using iteratively reweighted least squares with a bisquare weighting function ("robustfit" function from MATLAB 12.0 Statistical Toolbox) to explore the associations between:

a) Daily dietary intake (wave 1) and brain IDs (wave 2)

b) Daily dietary intake and blood parameters (obtained at both waves)

c) Brain IDs and blood parameters (both obtained at wave 2)

d) Blood parameters at waves 1 and 2 
Missing Value Analysis revealed patterns of missing data were random.

\section{Results}

\section{Sample characteristics}

Overall, from the subsample that underwent MRI, 72.8\% of the sample (62\% of the total sample) had detectable IDs (Figure 1) with a median volume of $40 \mathrm{~mm} 3$ (IQR=196 mm3), which represents $0.003 \%$ of the mean intracranial volume. Basal ganglia IDs were most common (70.6\% of the sample, median volume $=35 \mathrm{~mm} 3, \mathrm{IQR}=159.5 \mathrm{~mm} 3$ ) followed by IDs in the brainstem $(12.9 \%$ of the sample). IDs in the white matter $(6.1 \%)$, in the cortex/corticomedullary junction $(1.9 \%)$ and in the thalamus $(1.0 \%)$ were identified as micro-/macro haemorrhages with only two participants presenting mild superficial siderosis. The maximum volume of IDs in the basal ganglia (2768 mm3), cortex (440 mm3), white matter (1404 $\mathrm{mm} 3$ ) and thalamus (116 $\mathrm{mm} 3$ ) corresponded to previous haemorrhages in these regions, unlike in the brain stem (748 $\mathrm{mm} 3$ ) in which the smooth appearance of the IDs in its nuclei does not suggest their being caused by a single haemorrhagic episode. The main dietary sources of iron intake in this cohort are: bread and breakfast cereals (33\%), meat and meat products $(10 \%)$, and savoury foods and soups (9\%). A summary of the rest of the variables involved in the analyses appears in Table 1.

Associations between brain iron deposition and dietary intake

In this healthy ageing sample, brain IDs were not significantly associated with dietary iron intake, calorie or cholesterol intake after adjusting for age and gender (Table 2). This result was not different when the analysis was performed only including participants that had visible IDs on MRI.
Figure 1

Probability distribution of the brain iron deposits in the basal ganglia

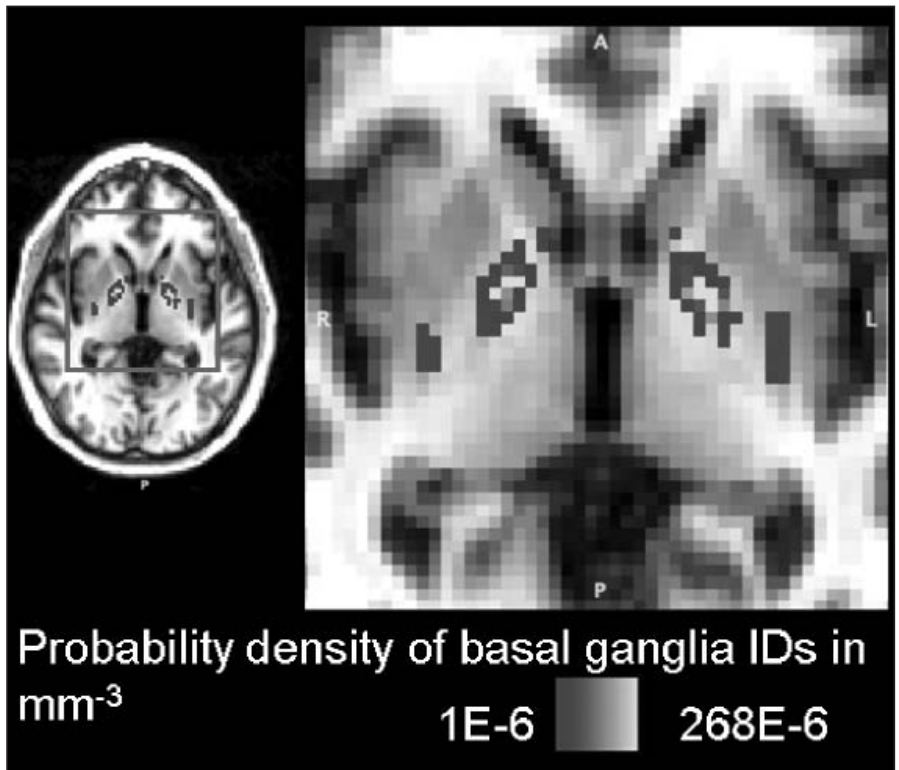

Associations between dietary intake and blood iron parameters

Red cell count was modestly and positively associated with calorie intake $(\mathrm{p}=0.03$ and 0.02 for waves 1 and 2 respectively). Mean cell volume was, on the contrary, negatively associated with calorie intake $(\mathrm{p}=0.05$ and 0.02 for waves 1 and 2 respectively). Ferritin was also negatively associated with calorie intake $(p=0.01)$. There were no significant associations between any of the dietary markers evaluated and haemoglobin or haematocrit levels (Table 2).

Table 1

Descriptive statistics of the parameters assessed in the sample

\begin{tabular}{|c|c|c|c|}
\hline Variable & Sample size & Median (IQR) for men & Median (IQR) for women \\
\hline Haemoglobin (130-180 g/L) - Wave 1 & 1063 (536 men) & $152(16)$ & $139(12)$ \\
\hline Red cell count (4.5-6.5 1012/L) - Wave 1 & 1062 (535 men $)$ & $4.78(0.52)$ & $4.44(0.44)$ \\
\hline Haematocrit (0.40-0.54 ratio) - Wave 1 & 1062 (535 men $)$ & $0.44(0.05)$ & $0.40(0.04)$ \\
\hline Mean cell volume (78.0-98.0 fL) - Wave 1 & 1062 (535 men) & $91.90(5.10)$ & $90.50(5)$ \\
\hline Daily iron intake (mg) & 928 (450 men) & $12.23(5.23)$ & $11.47(5.14)$ \\
\hline Daily energy intake (Kcal) & 928 (450 men) & $1924(755)$ & $1677.50(717)$ \\
\hline Daily cholesterol intake (mg) & 928 (450 men) & $280.50(155)$ & $245.5(116)$ \\
\hline Haemoglobin (130-180 g/L) - Wave 2 & 825 (429 men) & $146(18)$ & $136(13)$ \\
\hline Red cell count (4.5-6.5 1012/L) - Wave 2 & 824 (428 men) & $4.57(0.58)$ & $4.30(0.48)$ \\
\hline Haematocrit (0.40-0.54 ratio) - Wave 2 & 824 (428 men) & $0.42(0.05)$ & $0.39(0.04)$ \\
\hline Mean cell volume (78.0-98.0 fL) - Wave 2 & 824 (428 men) & $91.40(5.70)$ & $90.30(5.10)$ \\
\hline Ferritin $(20-300 \mathrm{ug} / \mathrm{L})-$ Wave 2 & $652(325$ men $)$ & $101(142.50)$ & $74(89)$ \\
\hline Transferrin Sat $(\%)-$ Wave 2 & 665 (331 men) & $29(13)$ & $25(66)$ \\
\hline Volume of iron deposits in intracranial volume $\left(\times 10^{-3}\right)(\%)$ & 676 (357 men) & $2.87(12.99)$ & $2.62(13.30)$ \\
\hline Total volume of iron deposits $\left(\mathrm{mm}^{3}\right)$ & $676(357$ men $)$ & $46(203)$ & $32(176)$ \\
\hline
\end{tabular}


Table 2

Results of the robust univariate regression analyses. Age and gender were used as covariates. Given: non-standardised $\beta$ (standard error, p-value)

\begin{tabular}{|c|c|c|c|c|c|c|c|}
\hline & $\begin{array}{l}\text { Daily iron } \\
\text { intake (mg) }\end{array}$ & $\begin{array}{l}\text { Daily energy } \\
\text { intake (Kcal) }\end{array}$ & $\begin{array}{l}\text { Daily cholesterol } \\
\text { intake (mg) }\end{array}$ & $\begin{array}{c}\text { Haemoglobin } \\
130-180 \mathrm{~g} / \mathrm{L} \text { - } \\
\text { Wave } 2 \\
\end{array}$ & $\begin{array}{c}\text { Red cell count } \\
\text { 4.5-6.5 1012/L - } \\
\text { Wave } 2 \\
\end{array}$ & $\begin{array}{c}\text { Haematocrit } \\
0.40-0.54 \text { ratio - } \\
\text { Wave } 2 \\
\end{array}$ & $\begin{array}{c}\text { Mean cell } \\
\text { volume 78.0-98.0 fL } \\
\text { - Wave } 2 \\
\end{array}$ \\
\hline Haemoglobin & 0.008 & $7.06 \times 10-6$ & $2.19 \times 10-4$ & 0.77 & - & - & - \\
\hline 130-180 g/L - Wave 1 & $(0.08,0.91)$ & $(5.38 \times 10-4,0.99)$ & $(0.003,0.94)$ & $(0.02,<0.001)$ & & & \\
\hline Red cell count & 0.003 & $3.90 \times 10-5$ & $1.20 \times 10-4$ & - & $0.84)$ & - & - \\
\hline 4.5-6.5 1012/L - Wave 1 & $(0.003,0.19)$ & $(1.81 \times 10-5,0.03)$ & $(1.03 \times 10-4,0.24)$ & & $(0.02,<0.001$ & & \\
\hline $\begin{array}{l}\text { Haematocrit } \\
0.40-0.54 \text { ratio - Waye } 1\end{array}$ & $\begin{array}{l}9.86 \times 10-5 \\
\end{array}$ & $1.20 \times 10-6$ & $\begin{array}{c}7.18 \times 10-6 \\
(88 \times 10-6030)\end{array}$ & - & - & 0.77 & - \\
\hline $0.40-0.54$ ratio - Wave 1 & $(2.23 \times 10-4,0.69)$ & $(1.55 \times 10-6,0.44)$ & $(8.68 \times 10-6,0.39)$ & & & $(0.02,<0.001)$ & \\
\hline $\begin{array}{l}\text { Mean cell volume } \\
78.0-98.0 \mathrm{fL} \text { - Wave } 1\end{array}$ & $\begin{array}{c}-0.03 \\
(0.03,0.30)\end{array}$ & $\begin{array}{c}-3.77 \times 10-4 \\
(1.96 \times 10-4,0.054)\end{array}$ & $\begin{array}{c}-0.001 \\
(0.001,0.24)\end{array}$ & - & - & - & $\begin{array}{c}0.97 \\
(0.01,<0.001)\end{array}$ \\
\hline Ferritin 20-300ug/L - & -1.37 & -0.01 & $-0.03(0.03,0.33)$ & 1.53 & 4.63 & 429.61 & 4.35 \\
\hline Wave 2 & $(0.78,0.08)$ & $(0.005,0.01)$ & & $(0.24,<0.001)$ & $(7.57,0.54)$ & $(87.68,<0.001)$ & $(0.63,<0.001)$ \\
\hline Transferrin Sat \% - Wave 2 & $\begin{array}{c}0.13 \\
(0.09,0.16)\end{array}$ & $\begin{array}{c}-8.70 \times 10-5 \\
(6.41 \times 10-4,0.89)\end{array}$ & $\begin{array}{c}-0.003 \\
(0.003,0.46)\end{array}$ & $\begin{array}{c}0.21 \\
(0.03,<0.001)\end{array}$ & $\begin{array}{c}0.19 \\
(0.82,0.81)\end{array}$ & $\begin{array}{c}60.99 \\
(9.79,<0.001)\end{array}$ & $\begin{array}{c}0.74 \\
(0.07,<0.001)\end{array}$ \\
\hline Total volume of IDs (mm3) & $\begin{array}{c}-0.09 \\
(0.82,0.91)\end{array}$ & $\begin{array}{l}5.13 \times 10-4 \\
(0.006,0.93)\end{array}$ & $\begin{array}{c}0.02 \\
(0.03,0.47)\end{array}$ & $\begin{array}{c}0.04 \\
(0.30,0.89)\end{array}$ & $\begin{array}{c}-8.18 \\
(8.76,0.35)\end{array}$ & $\begin{array}{c}-8.42 \\
(105.39,0.94)\end{array}$ & $\begin{array}{c}1.36 \\
(0.78,0.08)\end{array}$ \\
\hline $\begin{array}{l}\text { Percentage ID volume } \\
\text { in ICV }\left(\begin{array}{ll}\times & \left.10^{3}\right)\end{array}\right.\end{array}$ & $\begin{array}{c}-0.01 \\
(0.05,0.81)\end{array}$ & $\begin{array}{c}-5.33 \times 10-6 \\
(3.86 \times 10-4,0.99)\end{array}$ & $\begin{array}{c}9.56 \times 10-4 \\
(0.002,0.62)\end{array}$ & $\begin{array}{c}0.002 \\
(0.02,0.91)\end{array}$ & $\begin{array}{c}-0.51 \\
(0.58,0.38)\end{array}$ & $\begin{array}{c}-0.25 \\
(6.84,0.97)\end{array}$ & $\begin{array}{c}0.09 \\
(0.05,0.07)\end{array}$ \\
\hline $\begin{array}{l}\text { Haemoglobin } \\
130-180 \mathrm{~g} / \mathrm{L} \text { - Wave } 2\end{array}$ & $\begin{array}{c}0.12 \\
(0.10,0.23)\end{array}$ & $\begin{array}{c}6.37 \times 10-4 \\
(7.10 \times 10-4,0.37)\end{array}$ & $\begin{array}{c}5.32 \times 10-4 \\
(0.004,0.89)\end{array}$ & - & - & - & - \\
\hline $\begin{array}{l}\text { Red cell count } \\
4.5-6.51012 / \mathrm{L} \text { - Wave } 2\end{array}$ & $\begin{array}{c}0.006 \\
(0.003,0.07)\end{array}$ & $\begin{array}{c}5.35 \times 10-5 \\
(2.33 \times 10-5,0.02)\end{array}$ & $\begin{array}{c}1.27 \times 10-4 \\
(1.27 \times 10-4,0.32)\end{array}$ & - & - & - & - \\
\hline $\begin{array}{l}\text { Haematocrit } \\
0.40-0.54 \text { ratio - Wave } 2\end{array}$ & $\begin{array}{c}3.64 \times 10-4 \\
(2.89 \times 10-4,0.21)\end{array}$ & $\begin{array}{c}2.36 \times 10-6 \\
(2.03 \times 10-6,0.14)\end{array}$ & $\begin{array}{c}3.16 \times 10-6 \\
(1.10 \times 10-5,0.77)\end{array}$ & - & - & - & - \\
\hline $\begin{array}{l}\text { Mean cell } \\
\text { volume 78.0-98.0 fL - Wave 2 }\end{array}$ & $\begin{array}{l}-0.04 \\
(0.04,0.21)\end{array}$ & $\begin{array}{c}-5.79 \times 10-4 \\
(2.51 \times 10-4,0.02)\end{array}$ & $\begin{array}{c}-0.002 \\
(0.001,0.07)\end{array}$ & - & - & - & - \\
\hline
\end{tabular}

Associations between brain iron deposition and blood iron parameters

Brain IDs were not associated with any of the haematological variables assessed at the same wave of the MR scan (Table 2) and neither to the molecules associated with iron transport and storage.

Haematological parameters obtained at each wave were strongly and significantly associated $(\beta=0.77$ to $0.97 ; p<0.001)$ indicating high stability of the haematological measures over time. At wave 2, haemoglobin, haematocrit and mean cell volume were significantly associated with the non-heme iron transporters and storage proteins assessed $(\mathrm{p}<0.001)$ (Table 2$)$.

\section{Discussion}

In this large, narrow-age birth cohort of healthy older adults, dietary iron was not directly associated with haematological markers of iron or with the extent of MR visible brain IDs. Calorie and cholesterol daily intake were also not directly associated with the brain iron accumulation assessed from the MRI scans. Analyses of dietary patterns (20) and components of nutrient-rich diets (i.e. antioxidants and B vitamins) from this cohort in relation to cognitive function have been published previously $(21,22)$ and are beyond the scope of the current article. Exploration of the dietary sources of non-haem iron revealed that red meat contributed only $10 \%$ of the overall iron intake, with bread and fortified breakfast cereals being the main sources. As the relative bioavailability of iron from vegetable foods is highly variable, the results are not surprising.

Results reported by a previous study in rats fed a standard diet supplemented with carbonyl iron, found that the additional iron supplementation did not increase brain iron stores (23). Brain iron accumulation is known to be linked to misregulation of the brain iron metabolism and neurodegeneration (6). While, in animals, variations in dietary iron have been reported to alter iron metabolism (9), reports of hepcidin expression in the human central nervous system refer that the significance of this regulator of iron homeostasis is uncertain (24).

Despite calorie intake being directly associated with the count and size of red cells and with ferritin, it was not directly associated with the brain IDs detected on the MRI scans. Interestingly, a study on patients with HallervordenSpatz syndrome, a syndrome characterised by brain iron accumulation, reported that despite the presence of brain IDs, iron levels in the blood remained normal (25). However, as our sample consists of healthy older individuals, to extrapolate results of both studies requires an in-depth analysis of the mechanisms of brain iron accumulation, which is out of the scope of this paper.

We did not find an association between cholesterol intake and brain IDs. More research into the means by which a diet rich in cholesterol would affect the accumulation of nonheme iron in the brain is required. The study that showed that animals with a diet high in cholesterol experienced increased deposition of brain iron suggested that very high cholesterol in blood reduces the integrity of the blood-brain-barrier and/ or disrupts iron metabolism in ways which render the brain vulnerable to cholesterol-related cellular stress (13) but this hypothesis is still to be confirmed.

The disproportion in the load of IDs found in the basal 


\section{THE LOTHIAN BIRTH COHORT 1936}

ganglia and brainstem (prevalent in number and load perbrain) with respect to the other regions, mainly characterised by few microhaemorrhages, made unfeasible to do a regional analysis of the brain iron accumulation. The time (3 years) between the collection of dietary data and the MRI scans is a limitation of the study despite the strong association between the haematological parameters measured at both waves and the associations between two of them, measured 3 years apart, and calorie intake. While the narrow age range of the present sample is advantageous as it reduces the confounding effect of age, it limits the scope of the analysis to relatively healthy individuals on their early 70 s. It can be argued that the mineralised brain regions that also contain insoluble iron (26) were not assessed. Old micro-/macro-haemorrhages (>3 months from occurrence) can appear as calcified regions on conventional MRI $(26,27)$ and, therefore, not considered in the analysis. However, it is known that these calcified regions are strongly and directly associated with the IDs assessed (27). Therefore, given the significance values obtained, we don't expect that their inclusion would have changed the results of this study.

A previous study on a subsample of this cohort revealed that the brain IDs were negatively associated with cognitive abilities not only at ages 70 and 72 years old, but also at age 11 (2). Results from a study of dietary patterns on this cohort of healthy individuals showed that diet was no longer associated with cognitive function at old age after adjusting for childhood intelligence (tested at 11 years old) and socio-economic status (22), suggesting that the dietary influence on brain health and cognitive performance may be mediated via the lifelongstable trait of intelligence. A detailed characterisation of the basal ganglia IDs on MRI on a subsample of the same cohort concluded that the spatial distribution and multifocal morphology of these features suggest they could be associated with proximal mineralised lenticulostriate arteriolar walls and perivascular structures (28) having, therefore, mainly a vascular origin. The results of the present study reinforce the hypotheses derived from all these related findings.

To our knowledge, this is the first large study in humans to explore the association between calorie, iron and cholesterol intake and brain iron deposition. Our results suggest that neither iron, nor calorie or cholesterol intake at the levels found in normal western diets are directly associated with brain IDs assessed on conventional structural MRI scans of healthy older individuals, but that calorie intake plays a role in iron storage. More work is required to investigate the mechanisms of brain iron accumulation on normal individuals.

Acknowledgements: This work was funded by the Royal Society of Edinburgh through the Scottish Crucible Initiative. The LBC1936 Study was funded by Age UK and the UK Medical Research Council (http://www.disconnectedmind.ed.ac.uk/) (including the Sidney De Haan Award for Vascular Dementia). Funds from the Centre of Cognitive Ageing and Cognitive Epidemiology (http://www.ccace.ed.ac.uk/) (G0700704/84698), Row Fogo Charitable Trust, SINAPSE (Scottish Imaging Network A Platform for Scientific Excellence) collaboration, the Biotechnology and Biological Sciences Research Council, the Engineering and Physical Sciences Research Council and the Economic and Social Research Council are gratefully acknowledged. We thank the LBC1936 participants, nurses at the Wellcome Trust Clinical Research Facility, radiographers and other staff at the Brain Research Imaging Centre (http://www.sbirc.ed.ac.uk/): a SINAPSE collaboration Centre. We thank Dr Michael Allerhand, Statistician in the Centre for Cognitive Ageing and Cognitive Epidemiology, for overseeing and advising on the statistical analyses.

Competing interests: None

\section{References}

1. Zecca L, Youdim MBH, Riederer P, Connor JR and Crichton RR. Iron, brain ageing and neurodegenerative disorders. Nat Rev 2004;5:1-11. doi: 10.1038/nrn1537

2. Penke L, Valdés Hernández MC, Muñoz Maniega S, Gow AJ, Murray C, Starr JM, Bastin ME, Deary IJ, Wardlaw JM. Brain iron deposits are associated with general cognitive ability and cognitive ageing. Neurobiol Aging 2012;33:510-517. doi: 10.1016/j.neurobiolaging.2010.04.032

3. Brun A and Englund E. A white matter disorder in dementia of the Alzheimer type: a pathoanatomical study. Ann Neurol 1986;19:253-262. doi: 10.1002/ana.410190306

4. Snowdon DA. Healthy aging and dementia: findings from the Nun Study. Ann Intern Med 2003;139:450-454. doi: 10.7326/0003-4819-139-5_Part_2-200309021-00014

5. Faucheux BA, Bonnet AM, Agid Y and Hirsch EC. Blood vessels change in the mesencephalon of patients with Parkinson's disease. Lancet 1999;353:981-982. doi: 10.1016/S0140-6736(99)00641-8

6. Rouault TA, Cooperman S. Brain Iron Metabolism. Semin Pedriatr Neurol 2006;13:142-148. doi: 10.1016/j.spen.2006.08.002

7. Dallman PR, Siimes MA, Manies EC. Brain iron: persistent deficiency following short-term iron deprivation in the young rat. Br J Haematol 1975;31:209-215. doi: 10.1111/j.1365-2141.1975.tb00851.x

8. Erikson KM, Piñero DJ, Connor JR, Beard JL. Regional brain iron, ferritin and transferrin concentrations during iron deficiency and iron repletion in developing rats. J Nutr 1997;127:2030-2038. PMID:9311961

9. Piñero DJ, Li NQ, Connor JR, Beard JL. Variations in dietary iron alter brain iron metabolism in developing rats. J Nutr 2000;130:254-263. PMID: 10720179

10. Luchsinger JA, Mayeux R. Dietary factors and Alzheimer's disease. Lancet Neurol 2004;3:579-587. doi: 10.1016/S1474-4422(04)00878-6

11. Kastman EK, Willette AA, Coe CL, Bendlin BB, Kosmatka KJ, McLaren DG, Xu G, Canu E, Field AS, Alexander AL, Voytko ML, Beasley TM, Colman RJ, Weindruch RH \& Johnson SC. A calorie-restricted diet decreases brain iron accumulation and preserves motor performance in old rhesus monkeys. J Neurosci 2010;30:7940-7947. doi: 10.1523/JNEUROSCI.0835-10.2010

12. Cook CI, Yu BP. Iron accumulation in aging: modulation by dietary restriction. Mech Ageing Dev 1998;102:1-13. doi: 10.1016/S0047-6374(98)00005-0

13. Ghribi O, Golovko MY, Larsen B, Schrag M, Murphy EJ. Deposition of iron and $\beta$-amyloid plaques is associated with cortical cellular damage in rabbits fed with long-term cholesterol-enriched diets. J Neurochem 2006;99:438-449. PMID: 17029598

14. Deary IJ, Gow AJ, Taylor MD, Corley J, Brett C, Wilson V, Campbell H, Whalley LJ, Visscher PM, Porteous DJ \& Starr JM. The Lothian Birth Cohort 1936: a study to examine influences on cognitive ageing from age 11 to age 70 and beyond. BMC Geriatr 2007:7:28. doi: 10.1186/1471-2318-7-28

15. Wardlaw JM, Bastin ME, Valdés Hernández MC, Muñoz Maniega S, Royle NA, Morris Z, Clayden JD, Sandeman EM, Eadie E, Murray C, Starr JM \& Deary IJ. Brain Ageing, Cognition in Youth and Old Age, and Vascular Disease in the Lothian Birth Cohort 1936: Rationale, Design and Methodology of the Imaging Protocol. Intl J Stroke 2011;6:547-559. doi: 10.1111/j.1747-4949.2011.00683.x

16. Valdés Hernández MC, Maconick LC, Tan EJM, Wardlaw JM. Identification of mineral deposits in the brain on radiological images: a systematic review. Eur Radiol 2012;22:2371-2381. doi: 10.1007/s00330-012-2494-2

17. Glatz A, Valdés Hernández MC, Kiker AJ, Muñoz Maniega S, Royle NA, Bastin ME, Deary IJ, Wardlaw JM. Automatic segmentation of basal ganglia iron deposits from structural MRI. Publishing MIUA Online Proceedings 2011 at http://www. biomedical-image-analysis.co.uk/images/stories/glatz-posters1-32.pdf Accessed 24 February 2014

18. Valdés Hernández MC, Jeong TH, Murray C, Bastin ME, Chappell FM, Deary IJ, Wardlaw JM. Reliability of Two Techniques for Assessing Cerebral Iron Deposits with Structural Magnetic Resonance Images. J Magn Res Imag 2011;33:54-61. doi: $10.1002 /$ jmri.22361

19. Jia X, Craig LCA, Aucott LS, Milne AC, McNeill G (2008) Repeatability and validity of a food frequency questionnaire in free-living older people in relation to cognitive function. J Nutr Health Aging 2008;12:735-741. PMID: 19043649

20. Hsiao PY, Mitchell DC, Coffman DL, Allman RM, Locher JL, Sawyer P, Jensen GL, Hartman TJ. Dietary patterns and diet quality among diverse older adults: The University of Alabama at Birmingham Study of Aging. J Nutr Health Aging 2013;17:19-25. doi: 10.1007/s12603-012-0082-4

21. McNeill G, Jia X, Whalley LJ, Fox HC, Corley J, Gow AJ, Brett CE, Starr JM, Deary IJ. Antioxidant and B vitamin intake in relation to cognitive function in later life in the Lothian Birth Cohort 1936. Eur J Clin Nutr 2011;65:619-626. doi: 10.1038/ 


\section{JNHA: CLINICAL NEUROSCIENCES}

ejen.2011.2

22. Corley J, Starr JM, McNeill G, Deary IJ. Do dietary patterns influence cognitive function in old age? Intl Psychogeriatr 2013;25:1393-1407. doi: 10.1017/ S1041610213000793

23. Castellanos M, Puig N, Carbonell T, Castillo J, Martínez JM, Rama R, Dávalos A. Iron intake increases infarct volume after permanent middle cerebral artery occlusion in rats. Brain Res 2002;952:1-6. doi: 10.1016/S0006-8993(02)03179-7

22. Malik IA, NAZ N, Sheikh N, Khan S, Moriconi F, Blaschke M, Ramadori G. Comparison of changes in gene expression of transferrin receptor-1 and other ironregulatory proteins in rat liver and brain during acute-phase response. Cell Tissue Res 2011:344:299-312. doi: 10.1007/s00441-011-1152-3

25. Vinod Desai S, Bindu PS, Ravishankar S, Jayakumar PN, Pal PK. Relaxation and Susceptibility MRI Characteristics in Hallervorden-Spatz Syndrome. J Magn Res
Imag 2007;25:715-720. doi: 10.1002/jmri.20830

26. Valdés Hernández MC, Glatz A, Kiker AJ, Dickie DA, Aribisala BS, Royle NA Munoz Maniega S, Bastin ME, Deary IJ, Wardlaw JM. Differentiation of calcified regions and iron deposits in the ageing brain on conventional structural MR images. J Mag Res Imag, 2013; doi: 10.1002/jmri.24348 http://onlinelibrary.wiley.com/do /10.1002/jmri.24348/pdf Accessed 24 February 2014

27. Bradley WG. MR appearance of haemorrhage in the brain. Radiol 1993;189:15-26. PMID: 8372185

28. Glatz A, Valdés Hernández MC, Kiker AJ, Bastin ME, Deary IJ, Wardlaw JM Characterization of multifocal T2*-weighted MRI hypointensities in the basal ganglia of elderly, community-dwelling subjects. NeuroImage 2013;82:470-480. doi: 10.1016/j.neuroimage.2013.06.013 